\title{
Role of Carbon in Preventing the Intergranular Fracture in Iron-Phosphorus Alloys*
}

\author{
By Shigeru SUZUKI, ,* Minoru OBATA, ${ }^{* * *}$ Kenji $A B I K O^{* *}$ and \\ Hiroshi KIMURA**
}

\section{Synopsis}

$\mathrm{Fe}-\mathrm{P}$ alloys containing up to $0.67 w 1 \%$ phosphorus show intergranular fracture $(I G F)$ by an impact test after quenching from $1073 \mathrm{~K}$. Additions of up to about $0.01 \mathrm{wt} \%$ of carbon to the alloys prevents the intergranular fracture caused by the grain boundary segregation of phosphorus, and lowers the ductile-brittle transition temperature (DBTT). This effect is due to the segregation of carbon at grain boundaries. Aging at $873 \mathrm{~K}$ of the quenched specimen with $0.52 \% \mathrm{P}$ and $0.0008 \% \mathrm{C}$ lowers DBTT and increases the degree of grain boundary segregation of carbon while it does not affect the degree of grain boundary segregation of phosphorus. The grain boundary segregation of carbon strengthens the grain boundary cohesion and prevents intergranular fracture without removing phosphorus from grain boundaries.

$D B T T$ of the $\mathrm{Fe}-\mathrm{P}-\mathrm{C}$ alloys are analyzed in terms of the degree of grain boundary segregation of carbon and phosphorus and the solution hardening by phosphorus (the bulk concentration of phosphorus). The site-competition between carbon and phosphorus is taken into account in the calculation of the degree of segregation. It is found that the increase in the boundary cohesion by the carbon segregation is an important factor in preventing IGF.

\section{Introduction}

Phosphorus is a useful element in high strength sheet steel for automobiles because it improves the strength and the deep drawability of the steel. ${ }^{1)}$ In this sheet steel, carbon is usually reduced to less than about $0.01 \%$ to obtain high formability. However, if the steel is excessively decarburized, it becomes brittle through intergranular fracture $(\mathrm{IGF}) .^{2)}$ This phenomenon is also found in the Charpy impact test on $\mathrm{Fe}-\mathrm{P}-\mathrm{C}$ alloys. ${ }^{3)}$ Auger electron spectroscopy (AES) of the intergranular fracture facets shows that carbon segregated at grain boundaries suppresses IGF caused by the segregation of phosphorus.,3) Thus, in order to utilize the desirable effect of phosphorus, the mechanism of preventing IGF due to carbon should be clarified.

Three hypotheses have been proposed to explain the carbon effect on IGF. The first is the site competition hypothesis in which carbon atoms are considered to replace phosphorus segregated at grain boundaries and the decreased phosphorus segregation improves IGF. Erhart and Grabke ${ }^{4}$ and the authors ${ }^{5)}$ investigated the equilibrium grain boundary segregation of phosphorus and carbon in $\mathrm{Fe}-\mathrm{P}-\mathrm{C}$ alloys by AES, and showed that the segregation of phosphorus decreases with increasing carbon concentration in the bulk. This phenomenon can be interpreted with the site competition model. How- ever, it is not clear whether the degree of IGF depends only on the degree of phosphorus segregation and the decrease in the phosphorus segregation due to the site competition fully explains the effect of carbon preventing IGF.

The second is the chemical interaction hypothesis. In this hypothesis, carbon atoms are considered to change the nature of the atomic bond around phosphorus atoms and reduce the weakening effect of phosphorus on the grain boundary cohesion. This hypothesis requires an interaction between phosphorus and carbon at grain boundaries.

The last hypothesis is that carbon increases grain boundary cohesion by itself, irrespective of the phosphorus segregation.

Our previous research ${ }^{3)}$ supported the third mechanism. However, the site competition between carbon and phosphorus was not properly taken into account in the quantitative discussion of the ductilebrittle transition temperature (DBTT). In the present research, specimens with more varied concentrations of carbon and phosphorus than the concentrations in the previous research are investigated to take into account the site competition. The grain boundary segregation of both elements has been controlled by changing the bulk concentration of both elements and by quenching after aging at two temperatures. The degree of segregation has been measured by AES. The toughness and the mode of fracture have been examined together with the hardness and the grain size. With these results the mechanism of the effect of carbon preventing IGF is discussed.

\section{Experimental Procedure}

\section{Specimen Preparation}

Alloys were made from an electrolytic iron (Mairon, Toho Zinc. Co.), with $\mathrm{Fe}-25 \mathrm{wt} \% \mathrm{P}$ and $\mathrm{Fe}-4.5 \mathrm{wt} \% \mathrm{C}$ alloys as the mother alloys. The $\mathrm{Fe}-25 \% \mathrm{P}$ mother alloy was purchased and purified by remelting. The $\mathrm{Fe}-4.5 \% \mathrm{C}$ alloy was made by melting the electrolytic iron in a high purity graphite crucible under an argon atmosphere.

The electrolytic iron $(5 \mathrm{~kg})$ was vacuum melted in a calcium oxide crucible and deoxidized with the $\mathrm{Fe}-4.5 \% \mathrm{C}$ alloy. The $\mathrm{Fe}-\mathrm{P}-\mathrm{C}$ alloys were made by adding the $\mathrm{Fe}-25 \% \mathrm{P}$ mother alloy to the melt.

* Originally published in Tetsu-to-Hagané, 70 (1984), 2262, in Japanese. English version received on March 14, 1984; accepted in the final form on June 1, 1984. (C)1985 ISIJ

** Research Institute for Iron, Steel and Other Metals, Tohoku University, Katahira, Sendai 980.

*** Formerly Graduate School of Engineering, Tohoku University. Now at Metals and Ceramic Laboratory, R and D Center, Toshiba Co., Horikawa, Saiwai-ku, Kawasaki 210. 
Residual carbon resulting from deoxidation was utilized as the alloying element. The ingots were forged and rolled at temperatures between $1373 \mathrm{~K}$ and $1073 \mathrm{~K}$ to $6 \mathrm{~mm} \times 6 \mathrm{~mm}$ square rods. Specimens for Charpy type impact test $(4 \mathrm{~mm} \times 4 \mathrm{~mm} \times 55 \mathrm{~mm})$ and AES specimens $(3.6 \mathrm{~mm}$ in diameter and $32 \mathrm{~mm}$ in length) were taken from the rod.

The chemical composition of the alloys is given in Table 1. The carbon concentration of specimens is controlled by annealing under the flows of wet and dry hydrogen at $973 \mathrm{~K}$. The annealing conditions and the residual carbor concentrations $(\mathrm{wt} \%)$ are given in Table 2.

All specimens were heated at $1073 \mathrm{~K}$ for $1 \mathrm{~h}$ under a vacuum of about $1 \times 10^{-4}$ torr and quenched into an oil bath at $273 \mathrm{~K}$. Specimens aged at $873 \mathrm{~K}$ were quenched in a water bath at $273 \mathrm{~K}$.

\section{Mechanical Test and AES Measurement}

Charpy type impact test and micro-Vickers hardness test were performed. DBTT is taken as the temperature corresponding to the middle of the upper and lower shelf energies in the absorbed energy vs. temperature relation. Since the transition takes place within a narrow temperature range, DBTT is determined within $\pm 10 \mathrm{~K}$ and a quantitative analysis is possible. The amount of phosphorus and of carbon segregated at grain boundaries was measured by scanning Auger electron spectroscopy with PHI 590. The vacuum of the chamber was kept at about $5 \times 10^{-11}$ torr when fracturing the specimen and making measurements, so that no contamination of

Table 1. Compositions of the Fe-P-C alloys. (wt\%)

\begin{tabular}{c|ccccc} 
& P & G & O & Si & Mn \\
\hline Fe-0.11P & 0.11 & 0.036 & 0.0007 & 0.012 & 0.003 \\
$\mathrm{Fe}-0.34 \mathrm{P}$ & 0.34 & 0.040 & 0.0032 & 0.007 & 0.005 \\
$\mathrm{Fe}-0.52 \mathrm{P}$ & 0.52 & 0.022 & 0.0088 & 0.021 & 0.013 \\
$\mathrm{Fe}-0.67 \mathrm{P}$ & 0.67 & 0.024 & 0.0010 & 0.026 & 0.017
\end{tabular}

Table 2. Conditions of decarburization and the residual carbon concentration.* (wt\%)

\begin{tabular}{l|rllll} 
& $\begin{array}{l}1 W+ \\
1 D^{* *}\end{array}$ & $\begin{array}{l}2 W \\
2 D\end{array}$ & $\begin{array}{l}5 W+ \\
5 D\end{array}$ & $\begin{array}{l}12 W+ \\
5 D\end{array}$ & $\begin{array}{l}17 W+ \\
7 D\end{array}$ \\
\hline $\mathrm{Fe}-0.11 \mathrm{P}$ & 0.018 & 0.011 & 0.002 & 0.0014 & 0.0010 \\
$\mathrm{Fe}-0.34 \mathrm{P}$ & - & 0.010 & 0.002 & 0.0014 & 0.0010 \\
$\mathrm{Fe}-0.52 \mathrm{P}$ & 0.012 & 0.008 & 0.0021 & 0.0010 & 0.0008 \\
$\mathrm{Fe}-0.67 \mathrm{P}$ & 0.015 & 0.011 & 0.004 & 0.0023 & 0.0018
\end{tabular}

* For some specimens, the carbon concentration is given down to $1 \mathrm{ppm}$. The analysis was done with care and repeated several times. Values in the table are average figures. The scatter of data is given by error bars in the figure.

** $m W+n D$ indicates the decarburization for $m h$ in wet hydrogen $(W)$ and for $n h$ in dry hydrogen $(D)$. the fractured surface took place. ${ }^{6)}$

\section{Experimental Results}

\section{Mechanical Tests of Quenched Specimens}

Figure 1 shows the relation between DBTT and the bulk concentration of carbon for $\mathrm{Fe}-0.11,0.34,0.52$ and $0.67 \% \mathrm{P}$ alloys. They were heated for $1 \mathrm{~h}$ at $1073 \mathrm{~K}$ and quenched into an oil bath at $273 \mathrm{~K}$. The specimens fractured with the intergranular mode are indicated by the symbol IGF in the figure.* Specimens with about $0.01 \% \mathrm{C}$ and less were of single phase of ferrite. In specimens with $0.02 \% \mathrm{C}$ and more, pearlite nodules, which are the cause of DBTT increase, are observed. The specimens with $0.01 \% \mathrm{C}$ or less have the grain size of ASTM No. 5 and the grain size decreases with an increase in the carbon concentration above $0.02 \%$. The Vickers hardness of $0.34,0.52$ and $0.67 \% \mathrm{P}$ alloys with less than $0.01 \% \mathrm{C}$ were about 130, 160 and 180, respectively. Photograph 1 shows the effect of carbon on the mode of fracture in $\mathrm{Fe}-0.52 \% \mathrm{P}$ alloys tested at temperatures below DBTT. The fracture is predominantly intergranular in the low carbon specimens. Figure 2 shows AES results with the $0.52 \% \mathrm{P}$ alloys. In the alloy containing $0.0010 \% \mathrm{C}$ the Auger peak of carbon is barely observed, while in the alloy with $0.0021 \% \mathrm{C}$ the carbon peak is clearly observed. The results shown in Figs. 1 and 2 indicate that DBTT decreases with increases in the bulk concentration of carbon and IGF is completely prevented by the addition of about $0.01 \% \mathrm{G}$ in all the $\mathrm{Fe}-\mathrm{P}$ alloys. The carbon segregated at grain boundaries prevents IGF.

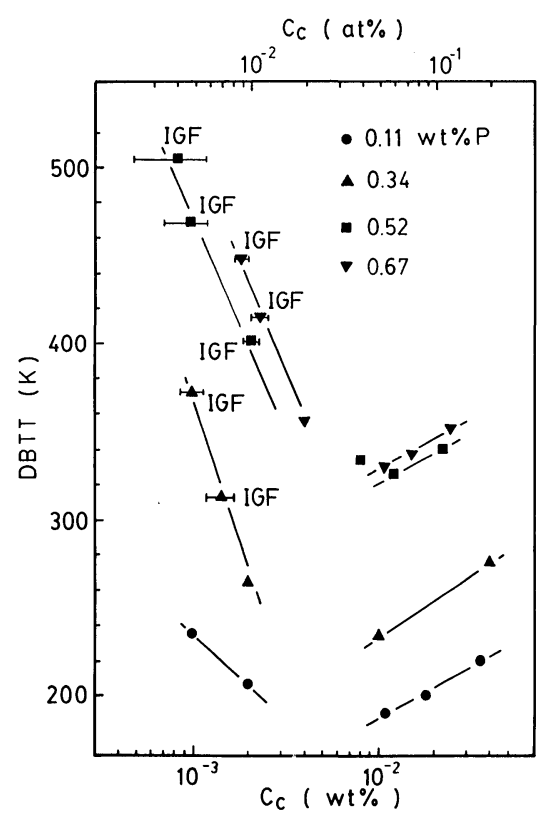

IGF means that the specimen showed intergranular fracture.

Fig. 1. Effect of carbon on the ductile-brittle transition temperature (DBTT) of Fe-P alloys.

* The present $0.1 \% \mathrm{P}$ alloys do not show IGF, while the low carbon $0.1 \% \mathrm{P}$ alloys in the previous research ${ }^{3)}$ did. DBTT are lower $^{-}$ in the present result than those of similar alloys in the previous result. These differences are due to the difference in the kind and amount of impurities between specimens in the two researches. 


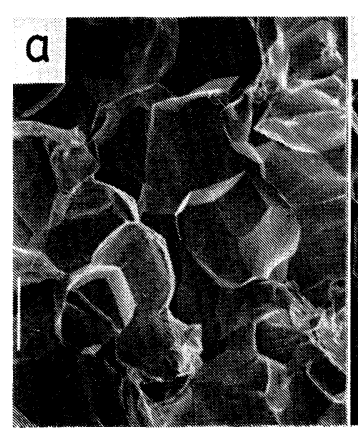

$0.0008 \mathrm{wt} \% \mathrm{C}$

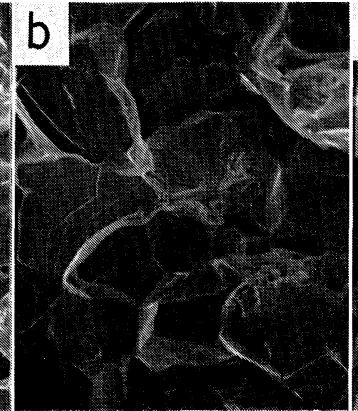

$0.0010 \mathrm{wt} \% \mathrm{C}$

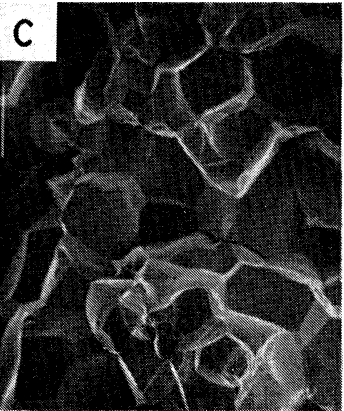

$0.0021 \mathrm{wt} \% \mathrm{C}$

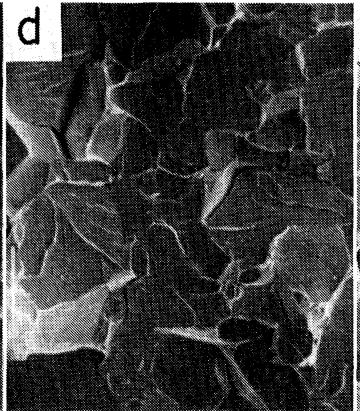

$0.008 \mathrm{wt} \% \mathrm{G}$

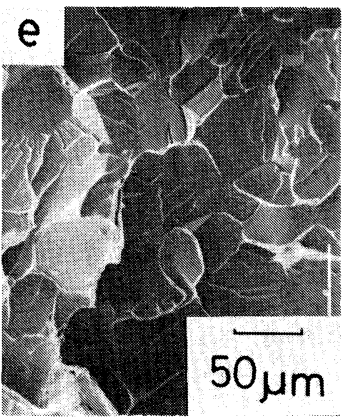

0.012 wto G

Photo. 1. Effect of carbon on the mode of fracture in $\mathrm{Fe}-0.52 \% \mathrm{P}$ alloys. The testing temperature is below DBTT in each specimen.

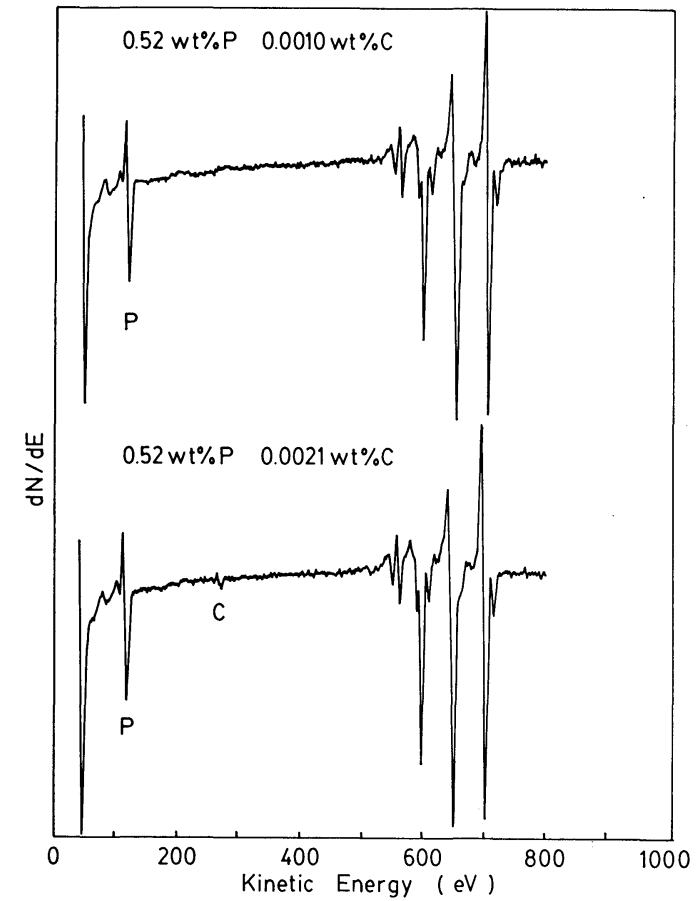

Fig. 2. Auger electron spectroscopy of grain boundary facet revealed by fracture of $\mathrm{Fe}-0.52 \% \mathrm{P}-\mathrm{C}$ alloys.

\section{Mechanical Tests and AES Measurement of Aged Specimens}

Figure 3 shows the effect of annealing at $873 \mathrm{~K}$ on DBTT and the segregation of phosphorus and carbon in an $\mathrm{Fe}-0.52 \% \mathrm{P}-0.0008 \% \mathrm{C}$ alloy. The grain size and hardness are shown along with DBTT. The scatter in AES data is due to the dependence of the segregation on the boundary plane orientation, ${ }^{5,6}$ ) and not due to the accuracy of measurement. The relative scatter of data is almost the same for carbon and phosphorus. The specimens were initially heated for $1 \mathrm{~h}$ at $1073 \mathrm{~K}$, where this alloy is in the ferrite region, and quenched to $273 \mathrm{~K}$. DBTT decreases by annealing at $873 \mathrm{~K}$. The mode of fracture is intergranular (more than $90 \%$ ) in every specimen. While the segregation of phosphorus, hardness and grain size are not affected, the segregation of carbon increases with annealing. This result clearly shows that carbon segregated at grain boundaries prevents

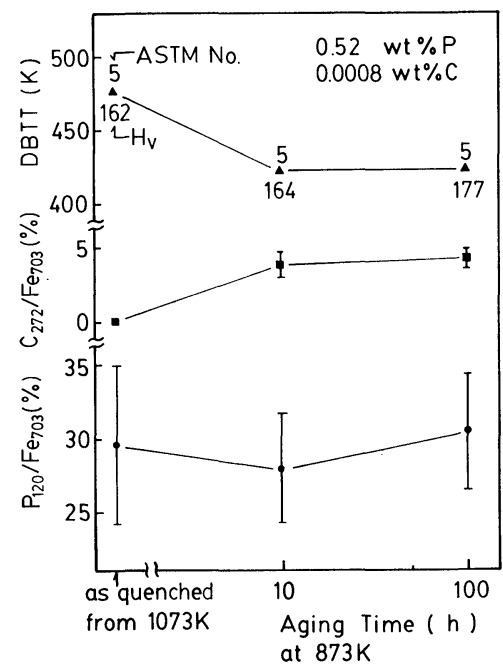

Fig. 3. Effect of aging at $873 \mathrm{~K}$ on DBTT and the degree of segregation of carbon and phosphorus in $\mathrm{Fe}-$ $0.52 \% \mathrm{P}-0.0008 \% \mathrm{C}$ alloys quenched from $1073 \mathrm{~K}$. ASTM number and the Vickers hardness are shown on the DBTT data.

the intergranular fracture by increasing the grain boundary cohesion without removing phosphorus from grain boundaries.

One may wonder why the degree of segregation of phosphorus does not decrease with the increase in the carbon segregation if the site competition exists. This is due to the choice of the aging temperature; calculation shows that the degree of segregation of phosphorus should remain unchanged by aging because the site competition cancels the otherwise increased phosphorus segregation by decreasing the temperature. ${ }^{5)}$

\section{Discussion}

\section{Contribution of the Segregation of Carbon and Phosphorus} to $D B T T$

The results shown in Fig. 3 clearly show that the site competition is not the sole mechanism for the effect of carbon on DBTT. It does not, however, completely rule out the site competition mechanism as a cause of the effect of carbon, since the site competition certainly exists between phosphorus and carbon. ${ }^{5)}$ It should be examined to what extent the site 
competition contributes to the decrease in DBTT shown in Fig. 1, and to what extent the increase in the carbon segregation itself does.

In the following, the contribution of the segregation of carbon and phosphorus to the change in DBTT is estimated by calculating the grain boundary coverage of each element and by comparing it to the experimentally observed change in DBTT. The grain boundary coverages* of phosphorus, $n_{\mathrm{P}}^{\mathrm{GB}}$, and of carbon, $n_{\mathrm{C}}^{\mathrm{GB}}$, are given by the following equations, respectively;

$$
n_{\mathrm{P}}^{\mathrm{GB}}=\frac{n_{\mathrm{P}} \exp \left(\frac{\Delta E_{\mathrm{P}}}{k T}\right)}{1+n_{\mathrm{P}}\left(\exp \left(\frac{\Delta E_{\mathrm{P}}}{k T}\right)-1\right)+n_{\mathrm{C}}\left(\exp \left(\frac{\Delta E_{\mathrm{P}}}{k T}\right)-1\right)}
$$

and

$$
n_{\mathrm{C}}^{\mathrm{GB}}=\frac{n_{\mathrm{C}} \exp \left(\frac{\Delta E_{\mathrm{C}}}{k T}\right)}{1+n_{\mathrm{P}}\left(\exp \left(\frac{\Delta E_{\mathrm{P}}}{k T}\right)-1\right)+n_{\mathrm{C}}\left(\exp \left(\frac{\Delta E_{\mathrm{C}}}{k T}\right)-1\right)}
$$

where, $n_{\mathrm{P}}, n_{\mathrm{C}}$ : the bulk concentration of phosphorus and carbon, respectively. ${ }^{5}$

The segregation energies of phosphorus and carbon, $\Delta E_{\mathrm{P}}$ and $\Delta E_{\mathrm{C}}$, respectively, have been estimated to be about $50 \mathrm{~kJ} / \mathrm{mol}$ and $80 \mathrm{~kJ} / \mathrm{mol}$, respectively.7,8) In Eqs. (1) and (2), the site competition between phosphorus and carbon is taken into account; phosphorus and carbon are assumed to occupy common sites at grain boundaries. Figure 4 shows the grain boundary coverage of phosphorus and carbon, $n_{\mathrm{P}}^{\mathrm{GB}}$

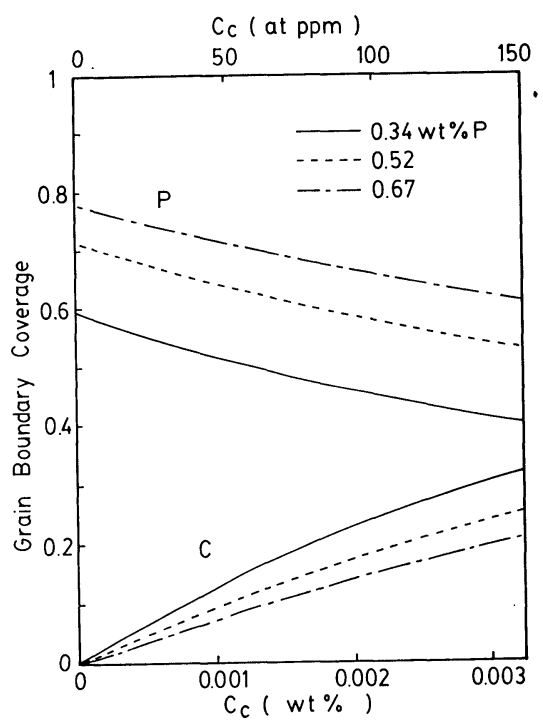

Fig. 4. Calculated grain boundary coverage of phosphorus and carbon in $\mathrm{Fe}-\mathrm{P}-\mathrm{C}$ alloys. The calculation was made with the segregation energies of phosphorus and carbon of 50 and $80 \mathrm{~kJ} / \mathrm{mol}$, respectively, and $T=1073 \mathrm{~K}$ and $n_{\mathrm{C}}^{\mathrm{GB}}$, respectively, calculated from Eqs. (1) and (2) for $1073 \mathrm{~K}$. To analyze the experimental results with the calculated degree of segregation, we consider that DBTT depends linearly on $n_{\mathrm{P}}^{\mathrm{GB}}$ and $n_{\mathrm{C}}^{\mathrm{GB}}$. This consideration is reasonable as already discussed in a previous paper. ${ }^{3)}$

1. Change in DBTT Caused by the Segregation of Garbon

The rate of change in DBTT with the change in $n_{\mathrm{C}}^{\mathrm{GB}}$ is estimated from the results of the aging experiment shown in Fig. 3. Aging at $873 \mathrm{~K}$ affects only the degree of segregation of carbon. Other factors contributing to DBTT, i.e., the degree of segregation of phosphorus and the plastic property of the matrix (the hardness), are not affected. Hence, the effect of $n_{\mathrm{C}}^{\mathrm{GB}}$ on DBTT can be estimated. The value of $n_{\mathrm{C}}^{\mathrm{GB}}$ in the alloy aged at $873 \mathrm{~K}$ is estimated to be $0.17 \pm$ 0.02 from the observed AES carbon peak and the relative sensitivity of Auger electrons of carbon. $n_{\mathrm{C}}^{\mathrm{GB}}$ $=0.18$ obtained from Eq. (2) agrees well with the experimental result. The coverage before aging is hardly detected by AES, and it is calculated to be 0.07 from Eq. (2). The increase in the grain boundary coverage of carbon, $n_{\mathrm{C}}^{\mathrm{GB}}$, by aging is thus estimated to be 0.11 . The decrease in DBTT by aging is $60 \mathrm{~K}$ (Fig. 3). The rate of change in DBTT by the segregation of carbon is $-550 n_{\mathrm{C}}^{\mathrm{GB}}(\mathrm{K})$ at a constant $n_{\mathrm{P}}^{\mathrm{GB}}$.

2. Change in DBTT Caused by the Segregation of Phosphorus and the Contribution of Site Competition to the Change in DBTT

The rate of change in DBTT with the change in $n_{\mathrm{P}}^{\mathrm{GB}}$ is estimated from the results in Fig. 1. DBTT decreases with the increase in the bulk concentration of carbon, $n_{\mathrm{C}}$, in each set of alloys with a constant phosphorus concentration. The hardness is practically determined only by the phosphorus concentration and not by the carbon concentration in specimens of interest here. Hence, the decrease in DBTT is attributed to the increase in $n_{\mathrm{C}}^{\mathrm{GB}}$ and to the decrease in $n_{\mathrm{P}}^{\mathrm{GB}}$ due to the site competition. In the $0.52 \% \mathrm{P}$ alloys, DBTT decreases from 510 to $410 \mathrm{~K}$ by increasing the bulk concentration of carbon, $n_{\mathrm{C}}$, from 0.0008 to $0.0021 \%$. Calculation from Eq. (2) indicates that $n_{\mathrm{C}}^{\mathrm{GB}}$ increases from 0.07 to 0.17 with the increase in $n_{\mathrm{C}}$ mentioned above. This increase in $n_{\mathrm{C}}^{\mathrm{GB}}, 0.10$, should reduce DBTT by $55 \mathrm{~K}$. The experimentally observed reduction in DBTT is $100 \mathrm{~K}$. The increase in $n_{\mathrm{C}}^{\mathrm{GB}}$ due to the increase in $n_{\mathrm{C}}$ causes about a half of the observed reduction in DBTT, and the remaining reduction, $45 \mathrm{~K}$, should be attributed to the decrease in $n_{\mathrm{P}}^{\mathrm{GB}}$ by the site competition. Calculation from Eq. (1) indicates that $n_{\mathrm{P}}^{\mathrm{GB}}$ decreases from 0.66 to 0.58 by the increase in $n_{\mathrm{C}}$ mentioned above. The decrease in $n_{P}^{\mathrm{GB}}$ by 0.08 reduces DBTT by $45 \mathrm{~K}$; the rate of change in DBTT due to the segregation of phosphorus is $560 n_{\mathrm{P}}^{\mathrm{GB}}$. Similarly, the comparison between the $0.0010 \% \mathrm{C}$ alloy with $0.0021 \% \mathrm{C}$ alloy gives the rate of $380 n_{\mathrm{P}}^{\mathrm{GB}}$. Here, the change in DBTT is $60 \mathrm{~K}$, and the change in $n_{\mathrm{C}}^{\mathrm{GB}}$ contributes $38 \mathrm{~K}$.

\footnotetext{
* Grain boundary coverage here means the fraction of the degree of segregation to saturation. It does not mean the concentration at the grain boundary. The saturated concentration for phosphorus is 25 at $\%$ on one boundary facet of the pair revealed by the intergranular fracture. ${ }^{6}$ ) The saturated concentration of carbon is assumed to be 25 at $\%$.
} 
The site competition contributes $22 \mathrm{~K}$, which is only about one third of the DBTT change. In the average, the rate of change in DBTT by the segregation of phosphorus is $(470 \pm 90) n_{\mathrm{P}}^{\mathrm{GB}}$ in the $0.52 \% \mathrm{P}$ alloys.

Similar calculations indicates that the contribution of the segregation of phosphorus is $200 n_{\mathrm{P}}^{\mathrm{GB}}$ in the $0.67 \% \mathrm{P}$ alloys and $1100 n_{\mathrm{P}}^{\mathrm{GB}}$ in the $0.34 \% \mathrm{P}$ alloys. The contribution of the site competition to the reduction in DBTT is only $20 \%$ in the $0.67 \% \mathrm{P}$ alloys and $60 \%$ in the $0.34 \% \mathrm{P}$ alloys. The data with the $0.34 \% \mathrm{P}$ and $0.67 \% \mathrm{P}$ alloys are less reliable than the results with the $0.52 \% \mathrm{P}$ alloys because the number of experimental points is only two in both series of alloys $(0.34 \%$ and $0.67 \% \mathrm{P})$. Even though this inaccuracy is taken into account, it may be concluded that the site competition hardly contributed more than a half of the DBTT decrease with the addition of carbon. We shall use the average value for the $0.52 \% \mathrm{P}$ alloys, $470 n_{\mathrm{P}}^{\mathrm{GB}}$, in later calculations as the contribution of the segregation of phosphorus.

\section{Mechanism of the Increase in Grain Boundary Cohesion due to Segregation of Carbon}

It has been shown that the segregation of carbon itself has the effect to prevent IGF; carbon segregated at grain boundaries increases grain boundary cohesion. Two hypotheses will be discussed as the cause of the increased cohesion; one is the chemical interaction hypothesis and the other is the intrinsic effect hypothesis.

\section{Chemical Interaction Hypothesis}

The chemical interaction hypothesis assumes that carbon atoms segregated at grain boundaries react with segregated phosphorus atoms and make them inactive in reducing grain boundary cohesion. This hypothesis seems to be unlikely. Firstly, no attractive interaction has been found between carbon and phosphorus. On the contrary, a repulsive interaction between them has been found by the activity measurement in liquid iron.9) Although the result obtained with liquid iron-where the elastic strain around solute atoms is negligible-would not be applicable to the case of grain boundary segregation, this result is unfavorable for the chemical interaction hypothesis.

The observed rate of change in DBTT due to changes in $n_{\mathrm{P}}^{\mathrm{GB}}$ and $n_{\mathrm{C}}^{\mathrm{GB}}$ also seems to be unfavorable to the chemical interaction hypothesis. The contribution of phosphorus at grain boundaries to DBTT is $470 n_{\mathrm{P}}^{\mathrm{GB}}$. If we assume that one carbon atom makes one phosphorus atom inactive at grain boundaries, and if the interaction between carbon and phosphorus is rather weak, the concentration of phosphorus made inactive by carbon is $n_{\mathrm{P}}^{\mathrm{GB}} \cdot n_{\mathrm{C}}^{\mathrm{GB}}$, and it should contribute to DBTT by $-470 n_{\mathrm{P}}^{\mathrm{GB}} \cdot n_{\mathrm{C}}^{\mathrm{GB}}$. Since $n_{\mathrm{P}}^{\mathrm{GB}}$ is about 0.7 in the range of concentrations of interest here (Fig. 4), the contribution of carbon to DBTT is estimated to be about $-330 n_{\mathrm{C}}^{\mathrm{GB}}$. On the other hand, the aging experiment indicates the contribution of carbon to be $-550 n_{\mathrm{C}}^{\mathrm{GB}}$. Thus, the above estimated contribution is smaller than observed. As for another approach to this problem, it should be possible to test the hypothesis by investigating the effect of carbon in alloys with various phosphorus concentrations because the contribution of carbon should depend on $n_{\mathrm{P}}^{\mathrm{GB}}$ in this hypothesis. In the present research, this approach is impossible because the experimental results were widely scattered.

\section{The Intrinsic Effect Hypothesis}

The intrinsic effect hypothesis, which considers that carbon segregated at grain boundaries itself increases the grain boundary cohesion, is the most likely mechanism. At present there is no direct evidence to strengthen the position of this hypothesis as the actually operating mechanism. However, since no other mechanism than those discussed above is thought of, it is reasonable to conclude that the effect of carbon increasing the grain boundary cohesion is the inherent nature of carbon.

There are at least two examples showing that carbon segregated at grain boundaries prevents IGF caused by reasons other than the segregation of phosphorus. One is the effect of carbon preventing IGF in pure molybdenum. ${ }^{10)}$ The other is the investigation of A. Kimura and H. Kimura. ${ }^{11)}$ They investigated the effect of carbon on the hydrogen induced intergranular fracture in high purity iron. About 80 at.ppm carbon completely prevents the intergranular fracture in an as-quenched (from $923 \mathrm{~K}$ ) specimen tested at $170 \mathrm{~K}$ under hydrogen charging. This effect of carbon has been shown also to be due to the segregation of carbon at grain boundaries. With their results we show below the chemical interaction hypothesis to be unlikely. In their specimen (quenched from $1073 \mathrm{~K}$ ), the grain boundary coverage of carbon is calculated to be less than 0.05 with the segregation energy, $80 \mathrm{~kJ} / \mathrm{mol}$. The diffusion of hydrogen is fast enough to realize the equilibrium segregation of hydrogen at $170 \mathrm{~K}$ during the test. The binding energy of hydrogen with an edge dislocation, $27 \mathrm{~kJ} / \mathrm{mol}{ }^{12}$ ) is assumed to be the segregation energy. The concentration of hydrogen in the matrix is assumed to be 10 at.ppm.* With these values, the grain boundary coverage is shown to be nearly $100 \%$. Thus, the concentration of hydrogen at grain boundaries is much larger than that of carbon segregated at grain boundaries. Nevertheless, carbon prevents IGF. This result is unfavorable to the chemical interaction mechanism, which requires concentrations of both elements to be comparable to each other. Thus, carbon segregated at grain boundaries prevents IGF, whatever its cause is and regardless of the concentration of carbon at grain boundaries relative to that of other harmful impurities. It is most natural to consider that the carbon effect is intrinsic.

The mechanism of how the segregated carbon increases the grain boundary cohesion is not yet known.

* The concentration of hydrogen under their experimental conditions is difficult to measure. This value is estimated from various experiments, i.e., hydrogen permeation. 
In order to discuss the mechanism, the atomistic process of the intergranular fracture should be clarified. It should also be noted here that the linearity between DBTT and the degree of grain boundary segregation (the grain boundary coverage) is also an empirical rule. To clarify the carbon effect preventing IGF more in detail, the atomistic mechanism of how DBTT is related to those variables should be clarified. Although these basic problems still remain unsolved, we consider that the present approach to revealing the role of carbon in preventing IGF is reasonable and the conclusions are, at least qualitatively, correct.

\section{Description of DBTT in Terms of $n_{\mathrm{P}}^{\mathrm{GB}}, n_{\mathrm{C}}^{\mathrm{GB}}$ and Solid Solution Hardening by Phosphorus}

The susceptibility to IGF, i.e., DBTT in a more specific term, is determined by the grain boundary cohesion, the plastic properties of the matrix and the grain size. The grain boundary cohesion is affected by segregation of impurities, and for the present alloys the contributions of $n_{\mathrm{P}}^{\mathrm{GB}}$ and $n_{\mathrm{C}}^{\mathrm{GB}}$ have been estimated. Contributions from other impurities, e.g., sulpher,* should also be discussed, but in the present alloys these are considered to be constant. The grain size is kept constant in the present research. Hence, if we estimate the contribution of the solid solution hardening by phosphorus to DBTT, DBTT of the present $\mathrm{Fe}-\mathrm{P}-\mathrm{C}$ alloys is described in terms of the above variables.

The contribution of solid solution hardening is estimated by comparing DBTT's of alloys with different phosphorus concentrations but with a fixed carbon concentration, e.g., $0.0010 \% * *$ The difference in DBTT between the $0.52 \% \mathrm{P}-0.0010 \% \mathrm{C}$ alloy and the $0.34 \% \mathrm{P}-0.0010 \% \mathrm{C}$ alloy is $100 \mathrm{~K}$ (Fig. 1). The differences in $n_{\mathrm{P}}^{\mathrm{GB}}$ and $n_{\mathrm{C}}^{\mathrm{GB}}\left(\Delta n_{\mathrm{P}}^{\mathrm{GB}}\right.$ and $\Delta n_{\mathrm{C}}^{\mathrm{GB}}$, respectively) between these two alloys are read from Fig. 4 to be 0.12 and -0.04 , respectively. (Note that $n_{\mathrm{C}}^{\mathrm{GB}}$ decreases with increasing $n_{\mathrm{P}}$ and hence $n_{\mathrm{P}}^{\mathrm{GB}}$.) Thus, the total contribution of $\Delta n_{\mathrm{P}}^{\mathrm{GB}}$ and $\Delta n_{\mathrm{C}}^{\mathrm{GB}}$ is $78 \mathrm{~K} ; \quad \Delta \mathrm{DBTT}=$ $470 \Delta n_{\mathrm{P}}^{\mathrm{GB}}-550 \Delta n_{\mathrm{C}}^{\mathrm{GB}}=78 \mathrm{~K}$. Hence, the contribution of solid solution hardening is $22 \mathrm{~K}$ for the difference in $n_{\mathrm{P}}$ of $0.18 \mathrm{wt} \%$. Thus, for $n_{\mathrm{P}}<0.5 \mathrm{wt} \%$, we may take the change in DBTT to be $120 \mathrm{~K}$ for $1 \mathrm{wt} \%$ change in $n_{\mathrm{P}}$.

A similar calculation is made for the combination of the $0.67 \% \mathrm{P}$ and the $0.34 \% \mathrm{P}$ alloys. If we linearly extrapolate*** the data for two $0.67 \% \mathrm{P}$ alloys to the carbon concentration of $0.0010 \%$, we find DBTT to be $500 \mathrm{~K}$. The difference in DBTT between the two alloys is $130 \mathrm{~K}$, and Fig. 4 gives $\Delta n_{\mathrm{P}}^{\mathrm{GB}}$ of 0.20 and $\Delta n_{\mathrm{C}}^{\mathrm{GB}}$ of -0.06 . The contribution of $\Delta n_{\mathrm{P}}^{\mathrm{GB}}$ and $\Delta n_{\mathrm{C}}^{\mathrm{GB}}$ is $127 \mathrm{~K}$. The contribution of solid solution hardening is almost null. The result is more different from the estimate above, $120 \mathrm{~K}$, for $n_{\mathrm{P}}<$
$0.5 \mathrm{wt} \%$. The difference may result from (1) the inaccuracy in the extrapolation and (2) the possibility that the solid solution hardening becomes less effective for the larger $n_{\mathrm{P}}$. The second possibility comes from the following facts. The hardness or the yield stress of solid solutions usually increases with the square root of the solute concentration. (The Vickers hardness of the present alloy is 130,160 and 180 for $0.34,0.52$ and $0.67 \mathrm{wt}^{\circ} \% \mathrm{P}$, respectively.) The plasticity of the matrix contributes less to the total energy of IGF for the weaker boundaries. ${ }^{13)}$ With increasing $n_{\mathrm{P}}$, the grain boundary cohesion decreases and the plastic work along grain boundaries during IGF also decreases. Thus, the contribution of solid solution hardening becomes less for larger $n_{\mathrm{P}}$. Although the linear relation between DBTT and $n_{\mathrm{P}}$ is not a good approximation, we take the contribution of solid solution hardening to be $100 n_{\mathrm{P}}\left(n_{\mathrm{P}}\right.$ in $\left.\mathrm{wt} \%\right)$ in the following calculation. The coefficient 100 is somewhat arbitrary, but may be a good approximation for alloys with $n_{\mathrm{P}}<0.5 \mathrm{wt} \%$.

In the range of the present investigation, DBTT is given by

$$
\operatorname{DBTT}(\mathrm{K})=470 n_{\mathrm{P}}^{\mathrm{GB}}-550 n_{\mathrm{C}}^{\mathrm{GB}}+100 n_{\mathrm{P}}+\text { const. }
$$

Here, $n_{\mathrm{P}}$ is given in $\mathrm{wt} \%$, and the constant term may be adjusted to obtain the best agreement between the calculated and the observed DBTT. Figure 5 gives the calculated DBTT together with the observed. The agreement is fairly good. The constant term is $150 \mathrm{~K}$. The contribution of each variable to DBTT is not very accurate numerically and

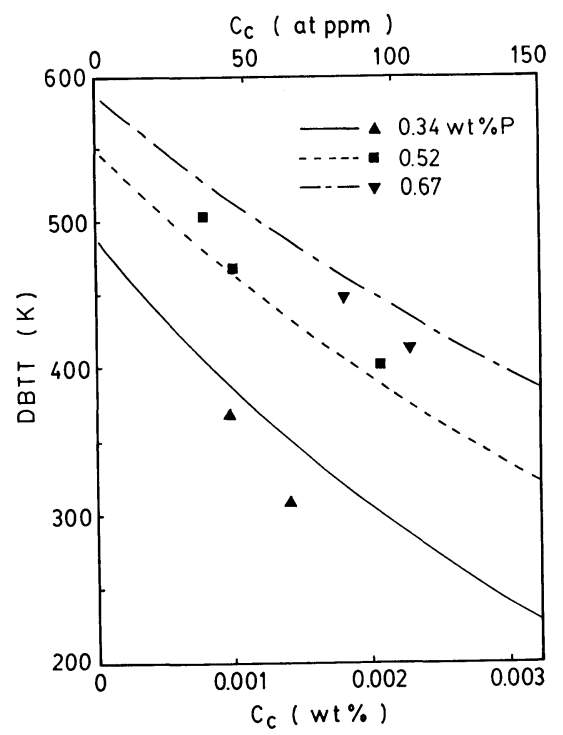

Fig. 5. DBTT calculated in terms of contributions of the grain boundary coverage of phosphorus and carbon and of the solution hardening. Experimental data are shown by squares and triangles.

* We have found that an electrolytic iron containing sulfer of about $20 \mathrm{wt}$. ppm shows IGF by impact test, but does not under the same experimental conditions if it contains several tens wt. ppm carbon.

** The difference in DBTT between two alloys with different phosphorus concentrations hardly depends on carbon concentration up to $0.003 \%$.

*** In Fig. 1, the horizontal axis is in the $\log n_{\mathrm{C}}$ scale. The extrapolation is made in the linear scale of $n_{\mathrm{C}}$, e.g., in Fig. 5. 
should not be considered to be valid beyond the present range of concentrations of phosphorus and carbon, but they give a general picture about the extent of the contribution of each variable to DBTT. It is obvious that the increase in grain boundary cohesion due to carbon segregation makes an important contribution to the change in DBTT.

We should make a remark here on the contribution of the plasticity to DBTT; the easier the plastic deformation of the matrix is, the lower DBTT is. The plasticity of the matrix is usually evaluated by the hardness measured at room temperature. When DBTT by impact test is near room temperature, the hardness cannot be a good measure of the plasticity in relation to IGF. This is so because the strain rate in impact test is much larger than hardness measurement and the plasticity usually depends on the strain rate. Hence, the above estimated contribution of the solid solution hardening to DBTT is only apparent, and may be used to represent DBTT phenomenologically.

\section{Conclusion}

The ductile-brittle transition temperature (DBTT), hardness, grain size, grain boundary fracture ratio and degree of grain boundary segregation of carbon and phosphorus were measured in Fe-P-C alloys. (The phosphorus concentration is $0.11,0.34,0.52$ and $0.67 \%$, and the carbon concentration from 0.0008 to $0.040 \%$.) Results are summarized as follows :

(1) After quenching from $1073 \mathrm{~K}$ in the ferrite region, DBTT decreases with increase in the bulk concentration of carbon up to $0.01 \%$, and it increases with further increases in the carbon concentration in all alloys with phosphorus up to $0.67 \%$.

(2) After quenching from $1073 \mathrm{~K}$, intergranular fracture is observed in alloys with 0.52 and $0.67 \%$ phosphorus when the concentration of carbon is less than $0.0023 \%$, and in alloys with $0.34 \%$ phosphorus and less than $0.0014 \%$ carbon. In $0.11 \% \mathrm{P}$ alloys the intergranular fracture is not observed.

(3) In the $\mathrm{Fe}-0.52 \% \mathrm{P}-0.0008 \% \mathrm{C}$ alloy quenched from $1073 \mathrm{~K}$, DBTT decreases and the degree of segregation of carbon increases by aging at $783 \mathrm{~K}$, while that of phosphorus remains unchanged. This fact shows that the segregation of carbon itself prevents intergranular fracture. Removal of phosphorus from grain boundaries by the segregation of carbon is not the sole cause of the effect of carbon preventing intergranular fracture.

(4) The change in DBTT with the bulk concentration of phosphorus and carbon is analyzed in terms of the degree of grain boundary segregation of phosphorus and carbon and solution hardening by phosphorus. The inherent effect of segregated carbon increasing grain boundary cohesion is shown to be an important cause of the effect of carbon preventing intergranular fracture.

\section{Acknowledgements}

The electrolytic iron was donated by Toho Zinc. Co. The present research has been partially supported financially by Grant-in-Aid for Co-operative Research from the Ministry of Education, Science and Culture, and by a fund from Nippon Steel Corporation. The authors deeply thank all of them.

\section{REFERENCES}

1) H. Hu: Texture of Cryst. Sol., 2 (1976), 113 and 4 (1980), 13.

K. Matsudo, K. Osawa and M. Sakai: Tetsu-to-Hagané, 64 (1978), S722.

T. Ono, T. Shimomura, K. Osawa and K. Matsudo: Tetsu-to-Hagané, 67 (1981), S457; Trans. ISIJ, 21 (1981), B453.

H. Takechi, H. Katoh, K. Koyama, K. Kawai and H. Toyota: Tetsu-to-Hagané, 68 (1982), 1355.

2) M. Konishi, T. Obata, T. Tanaka, N. Ohashi and Y. Ohashi: Tetsu-to-Hagané, 65 (1979), A97.

3) K. Abiko, S. Suzuki and H. Kimura: Trans. Japan Inst. Metals, 23 (1982), 43.

4) H. Erhart and H. J. Grabke: Met. Sci., 15 (1981), 401.

5) S. Suzuki, M. Obata, K. Abiko and H. Kimura: Scripta Met., 17 (1983), 1325.

6) S. Suzuki, K. Abiko and H. Kimura: Trans. ISIJ, 23 (1983), 746.

7) H. J. Grabke, W. Panlitschke, G. Tauber and H. Vief haus: Surf. Sci., 63 (1977), 377.

8) J. Q. Glayton and J. F. Knott: Met. Sci., 16 (1982), 145.

9) S. Ban-ya, N. Maruyama and S. Fujino: Tetsu-to-Hagané, 69 (1983), 921.

10) S. Suzuki, H. Matsui and H. Kimura: Mat. Sci. Eng., 47 (1981), 209.

11) A. Kimura and H. Kimura: J. Japan Inst. Metals, 47 (1983), 807.

12) J. P. Hirth: Met. Trans., 11A (1980), 861.

13) C. J. McMahon, Jr. and V. Vitek: Acta Met., 27 (1979), 507. 